\title{
GMR
}

\section{Isolation and characterization of white and brown adipocytes in Kunming mice}

\author{
Y.W. Nie*, P. Zhang*, J. Zhang, H.Y. Liang, M. Wang, B. Dai, H. Liang \\ and D.J. Liu
}

The Key Laboratory of China Education Ministry for Research of Mammal

Reproductive Biology and Biotechnology, Inner Mongolia University, Hohhot, China

*These authors contributed equally to this study.

Corresponding author: D.J. Liu

E-mail: nmliudongjun@aliyun.com

Genet. Mol. Res. 15 (1): gmr.15017355

Received August 4, 2015

Accepted November 13, 2015

Published February 26, 2016

DOI http://dx.doi.org/10.4238/gmr.15017355

ABSTRACT. White adipose tissue and brown adipose tissue play critical roles in controlling energy homeostasis and the development of obesity and diabetes. We isolated mouse white adipocytes from inguinal white fat tissues and brown adipocytes from interscapular brown fat tissues, and employed a variety of approaches, including immunofluorescent staining, quantitative real-time PCR, western blotting analysis, and differentiation assay, to characterize those adipocytes. Both white and brown adipocytes stained positively for CD44 and CD29, and lipid droplets were observed after the induction of adipogenesis. The Asc1 expression level in the white adipocytes was 2.5-fold higher than that in the brown adipocytes $(P<0.05)$, and the expression of Ucp1 in the white adipocytes was approximately $50 \%$ of that in the brown adipocytes $(P<0.05)$. The expression of $\alpha$-tubulin in the brown adipocytes was approximately $70 \%$ of that in the white adipocytes. The brown adipocytes had a higher Cidea mRNA level $(P<$ $0.05)$ and a lower Ppar $\gamma$ mRNA level $(P<0.05)$ than the white adipocytes. The results demonstrate that white and brown adipocytes have different 
gene expression signatures, and may represent two useful cell models to study the mechanisms involved in obesity.

Key words: White adipocytes; Brown adipocytes; Asc1; Ucp1; Adipocyte differentiation

\section{INTRODUCTION}

Obesity has reached pandemic levels (Caballero, 2007). The majority of weight gain in obese humans is characterized by an increase in adipose mass (Gesta et al., 2007), eventually resulting in certain disorders such as hyperlipidemia or diabetes. White adipocytes are unilocular with a large lipid droplet surrounded by a thin layer of cytoplasm, and few mitochondria (Cinti, 2005; Au-Yong et al., 2009; Richard and Picard, 2011). White adipose tissue (WAT) stores excess energy in the form of triacylglycerol that can release free fatty acids into the system during a lack of nutrition (Attie and Scherer, 2009; Haas et al., 2012). Brown adipocytes are cells that are rich in mitochondria and have cytoplasm containing multilocular lipid droplets (Golozoubova et al., 2001). Brown adipose tissue (BAT) dissipates chemical energy to protect against hypothermia and obesity through a process termed nonshivering thermogenesis, which has greatly increased the interest in adipose tissue (Wu et al., 2012).

Mice can have both inguinal white fat depots (Xue et al., 2005; Waldén et al., 2012) and interscapular depots of classical brown adipocytes over their lifetime (Rosenwald et al., 2013). A range of studies have demonstrated that white and brown adipocytes are not sister cells (Atit et al., 2006). Brown adipocytes convey the gene signature of myocytes, and the interscapular and perirenal BAT depots of rodents are derived from a MYF5 muscle-like cellular lineage (Seale et al., 2008). White adipocytes develop from pericytes that derive from the lateral mesoderm (Tang et al., 2008).

Here, we report the isolation of white and brown adipocytes by collagenase type II, and describe the immunophenotype, differentiation potential, and Asc1, Ucp1, Ppar $\gamma$, Cidea, and $\alpha$-tubulin expression levels in white and brown adipocytes. The study may provide experimental support for the use of white and brown adipocytes as models.

\section{MATERIAL AND METHODS}

\section{Animals}

Kunming strain mice ( 7 days old) were provided by the Experimental Animal Center, Inner Mongolia University. The white and brown adipose tissue was obtained from the inguinal and interscapular regions of the mice, respectively. All experiments were performed according to the Animal Ethics Committee of Inner Mongolia University.

\section{White and brown adipocytes isolation}

The inguinal WAT and interscapular BAT tissues were washed thoroughly with sterile phosphate-buffered saline (PBS) to remove blood cells. The tissues were then minced and digested with $0.2 \%$ collagenase type II at $37^{\circ} \mathrm{C}$ for $1 \mathrm{~h}$ while shaking with moderate vigor. The cells were centrifuged at $1500 \mathrm{~g}$ for $5 \mathrm{~min}$ to remove the suspended material, and plated on a collagen-coated Petri dish. Cells were cultured in a medium comprising Dulbecco's modified Eagle's medium/ 
nutrient mixture F-12 (DMEM/F12), 10\% fetal bovine serum (FBS) and $100 \mathrm{U}$ penicillin, and 100 $\mu \mathrm{g} / \mathrm{mL}$ streptomycin at $37^{\circ} \mathrm{C}$ in $5 \% \mathrm{CO}_{2}$.

\section{Immunofluorescent staining}

Cells were fixed with $4 \%$ paraformaldehyde, then permeabilized with $0.25 \%$ Triton X-100. The cells were stained with primary antibodies against CD44, CD29, HLA-DR, CD34 (BIOSS, CN), ASC-1 (sc-292032, Santa Cruz, CA, USA), Ucp1 (ab10983, Abcam, UK), $\alpha$-tubulin (ab15246, Abcam), and GAPDH (ab9485, Abcam) overnight at $4^{\circ} \mathrm{C}$. After washing twice with PBS, the cells were incubated with fluorescein isothiocyanate-labeled secondary antibodies at room temperature for $1 \mathrm{~h}$. PBS took the place of primary antibodies in the negative controls.

\section{Western blotting analysis}

Western blotting was performed as described previously (Shan et al., 2013). Whole cell lysates were prepared from cells in radio-immunoprecipitation assay buffer [50 mM Tris- $\mathrm{HCl}, \mathrm{pH}$ 8.0; $150 \mathrm{mM} \mathrm{NaCl} ; 1 \% \mathrm{NP}-40 ; 0.5 \%$ sodium deoxycholate; and $0.1 \%$ sodium dodecyl sulfate (SDS)] supplemented with a protease inhibitor cocktail on ice. The protein concentrations were measured using the BCA Protein Assay Kit (23225, Thermo, USA). Protein $(10 \mathrm{mg}$ ) was separated by SDS polyacrylamide gel electrophoresis (SDS-PAGE), transferred onto polyvinylidene difluoride (PVDF) membranes, and incubated with primary antibodies overnight at $4^{\circ} \mathrm{C}$. The proteins on the PVDF membranes were visualized with Thermo Scientific Pierce ECL western blotting substrate using the Tanon 5200 (Tanon, CN) detection system. The experiment was repeated at least three times.

\section{Quantitative real-time polymerase chain reaction (qPCR) and reverse transcription PCR (RT-PCR)}

Total RNA was extracted using TRizol reagent (TaKaRa, CN), according to the manufacturer instructions. RNA was treated with gDNA Eraser to eliminate genomic DNA. Complementary DNA (cDNA) was synthesized using Prime Script RT Enzyme Mix I (TaKaRa). qPCR was conducted using a 7500 Real-Time PCR system. The Ct value of GAPDH was used as internal control, and the $2^{-\Delta \Delta C T}$ method was used to analyze relative expression levels. RT-PCR was carried out as described previously (Nie et al., 2013). All measurements were repeated at least three times. The primers are listed in Table 1.

\section{Adipogenic differentiation}

Upon the cells reaching $80 \%$ confluence, the cells were cultured in induction medium (90\% DMEM/F12, 10\% FBS, $1 \mu \mathrm{M}$ dexamethasone, $0.5 \mathrm{mM}$ 1-methyl-3-isobutylxanthine, $10 \mu \mathrm{g} /$ $\mathrm{mL}$ insulin). After two days of induction, the medium was replaced with a differentiation medium (90\% DMEM/F12, 10\% FBS, $5 \mu \mathrm{g} / \mathrm{mL}$ insulin) for two days. Cells were cultured in DMEM/F12 with $10 \%$ FBS as controls. The cells were fixed with $4 \%$ paraformaldehyde for 15 min, then stained with Oil-Red $\mathrm{O}$ working solution for $30 \mathrm{~min}$. After staining, the cells were washed with $60 \%$ isopropanol and imaged. 
Table 1. Sequences of primers used for quantitative real-time PCR (qPCR) and reverse transcription polymerase chain reaction (RT-PCR).

\begin{tabular}{|c|c|}
\hline Gene & Primer $\left(5^{\prime}-3^{\prime}\right)$ \\
\hline \multirow{2}{*}{ Asc1 } & TCGTGGGAAAGATGTGGAGTT \\
\hline & CTGGGACAAGCAATCAATAAGGT \\
\hline \multirow[t]{2}{*}{ Ucp1 } & CACTCAGGATTGGCCTCTACGAC \\
\hline & GCTCTGGGCTTGCATTCTGAC \\
\hline \multirow[t]{2}{*}{ Ppary } & CCTTGCTGTGGGGATGTCT \\
\hline & GATTTGTCCGTTGTCTTTCCTGT \\
\hline \multirow[t]{2}{*}{ Cidea } & TGACATTCATGGGATTGCAGACTAA \\
\hline & TCCAGCACCAGCGTAACCAG \\
\hline \multirow[t]{2}{*}{$\alpha$-tubulin } & TGAGAGCAACTCGACACTCTCGT \\
\hline & TGAGAGCAACTCGACACTCTCGT \\
\hline \multirow[t]{2}{*}{ Gapdh } & CACGATGGAGGGGCCGGACTCATC \\
\hline & TAAAGACCTCTATGCCAACACAGT \\
\hline \multirow[t]{2}{*}{ Ppary (RT-PCR) } & GTCACACTCTGACAGGAGCC \\
\hline & GGGTGGGACTTTCCTGCTAA \\
\hline
\end{tabular}

\section{Statistical analysis}

Data are reported as means \pm SEM. Statistical analysis was achieved by the Student $t$-test using the SPSS 17.0 software. Statistical significance was accepted at $P$ values less than 0.05 .

\section{RESULTS}

\section{Morphological characteristics of white and brown adipocytes}

White and brown adipocytes started to adhere after 6-8 $\mathrm{h}$ cultivation. The cells had grown fusiform or triangular tentacles $48 \mathrm{~h}$ later. The cells showed fibroblast-like morphological characteristics.

\section{Immunofluorescence staining}

After immunofluorescent staining, the CD44 and CD29 markers were positive and the HLA-DR and CD34 markers were negative for white and brown adipocytes (Figure 1). Asc1 in the white adipocytes was mainly localized in the nuclei (Figure 2A). Brown adipocytes were uniformly stained (Figure 2B). The fluorescence signal of Ucp1 in the brown adipocytes was stronger than in the white adipocytes (Figure $2 \mathrm{C}$ and $\mathrm{D}$ ). We also noticed that there was a clear difference in the $\alpha$-tubulin fluorescence signal between the white and brown adipocytes (Figure 3C).

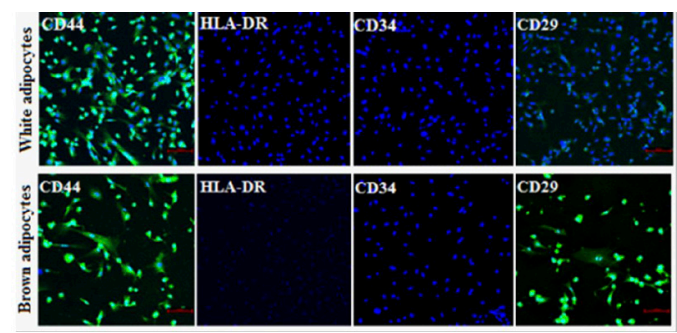

Figure 1. Immunofluorescence staining of CD44, HLA-DR, CD34, and CD29 in white and brown adipocytes. White and brown adipocytes were positive for CD29 and CD44, and negative for HLA-DR and CD34. Bar represents $100 \mu \mathrm{m}$. 


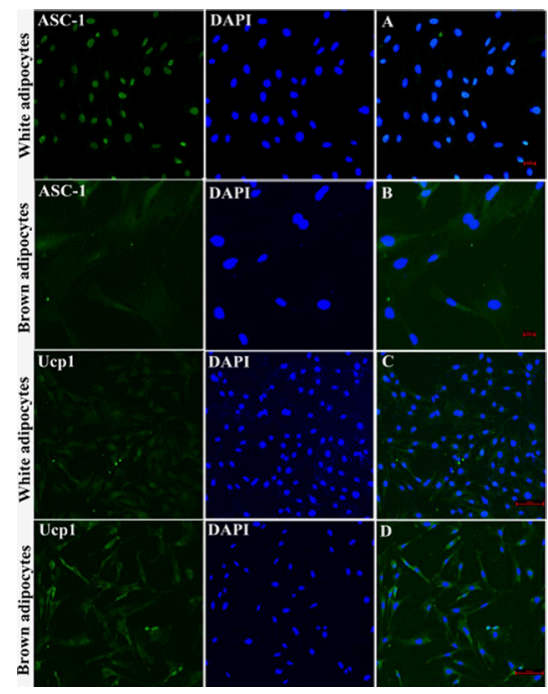

Figure 2. Immunofluorescence staining of Asc1 and Ucp1 in white and brown adipocytes. Images from immunofluorescent staining of Asc1, Ucp1 (green), and DAPI staining of nuclei (blue) were displayed.
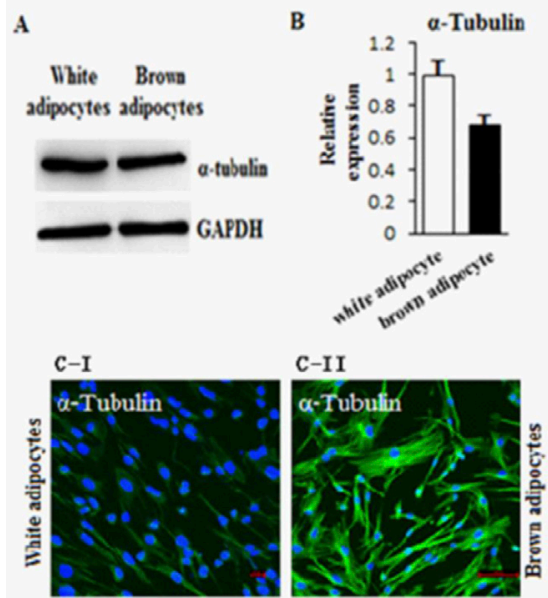

Figure 3. Expression of $\alpha$-tubulin in white and brown adipocytes. A. Western blotting analysis of $\alpha$-tubulin in white and brown adipocytes. B. qPCR analysis of $\alpha$-tubulin expression in white and brown adipocytes. C. Immunofluorescence staining of $\alpha$-tubulin in white and brown adipocytes. GAPDH was used as control. Data are reported as means \pm SEM. Bar represents $10 \mu \mathrm{m}$.

\section{Expression of Asc1, Ucp1, Ppary, Cidea, and $\alpha$-tubulin in the white and brown adipocytes}

The qPCR and western blotting analysis results showed that the expression of Asc1 in the white adipocytes was 2.5 -fold higher than in the brown adipocytes $(P<0.05)$, while the expression of Ucp 1 in the white adipocytes was $50 \%$ of that in the brown adipocytes $(P<0.05)$ (Figure 4). 


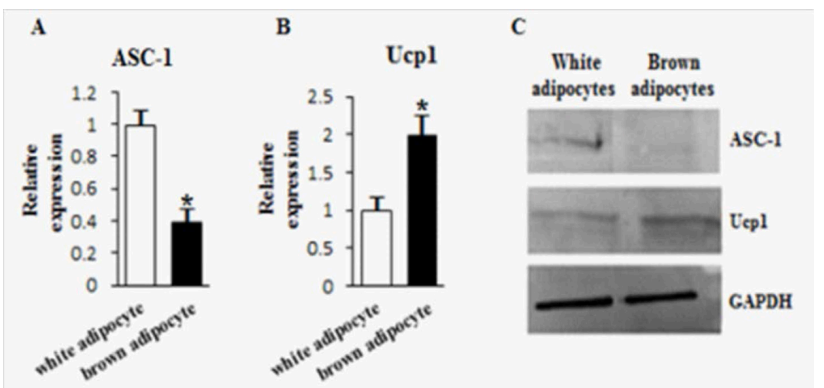

Figure 4. Expression of Asc1 and Ucp1 in white and brown adipocytes. A. qPCR analysis of Asc1 in white and brown adipocytes ( $\left.{ }^{*} P<0.05\right)$. B. $q P C R$ analysis of Ucp1 in white and brown adipocytes $\left({ }^{*} P<0.05\right)$. C. Western blotting analysis of Asc1 and Ucp1 in white and brown adipocytes. The Asc1 and Ucp1 expression levels were normalized to GAPDH. Data are reported as means \pm SEM.

Cidea showed a 2.0-fold higher expression in the brown adipocytes than in the white adipocytes (Figure 5A). The RT-PCR and qPCR analyses revealed that there was higher expression of the adipogenic-specific marker Ppar $\gamma$ mRNA in the white adipocytes (Figure 5B and C).
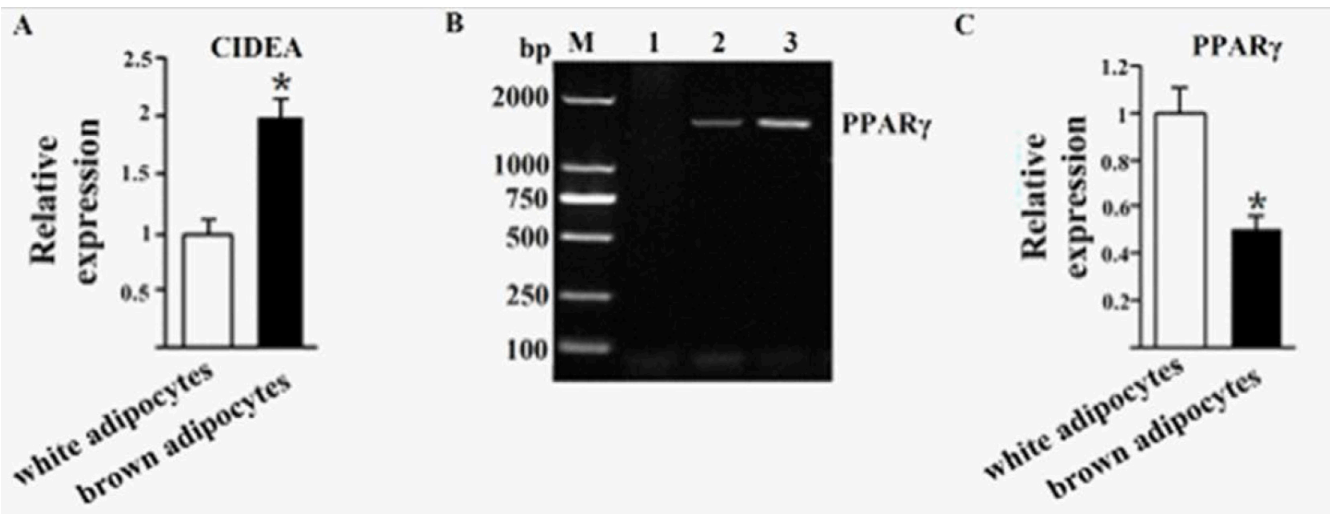

Figure 5. Expression of Cidea and Ppary in white and brown adipocytes. A. qPCR analysis of Cidea in white and brown adipocytes ( $\left.{ }^{*} P<0.05\right)$. B. RT-PCR analysis of Ppary in white and brown adipocytes, Lane M: DL2000; lane 1: negative control; lane 2: brown adipocytes; lane 3: white adipocytes. C. qPCR analysis of Ppary in white and brown adipocytes. $\left({ }^{*} \mathrm{P}<0.05\right)$. GAPDH was used as control. Data are reported means \pm SEM.

Additionally, the western blotting and qPCR results indicated that the expression levels of $\alpha$-tubulin in the brown adipocytes were approximately $70 \%$ of those in the white adipocytes (Figure $3 A$ and $B)$.

\section{Adipogenic differentiation of the white and brown adipocytes}

After induced differentiation and Oil Red-O staining, more than $80 \%$ of the cells were stained with Oil Red-O showing numerous red lipid droplets; most red lipid droplets were filled within the cytoplasm and located at the periphery of the nucleus (Figure 6). The red lipids were also observed in the control groups of white and brown adipocytes. 


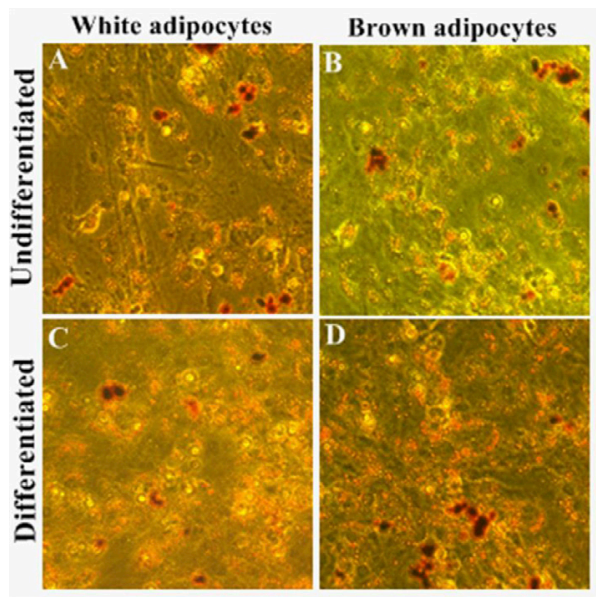

Figure 6. Adipogenic differentiation of white and brown adipocytes. Morphological observation and Oil Red-O staining of the adipogenic differentiation. A. Control group of white adipocytes. B. Control group of brown adipocytes. C. White adipocytes adipogenic differentiation for 7 days. D. Brown adipocytes adipogenic differentiation for 7 days.

\section{DISCUSSION}

Obesity is associated with an increased number of adipocytes (Faust et al., 1978). Brown fat is specialized for energy expenditure, and its function has therefore been proposed as a defense against obesity. Recently, brown fat progenitors have been identified in skeletal muscle and white fat in humans (Guerra et al., 1998; Elabd et al., 2009). This discovery presents the potential for increasing the oxidative capacity of these tissues by targeting endogenous precursor cells to differentiate in vivo into energy-dissipating brown adipocytes (Schulz et al., 2011). However, white and brown adipocytes often occur mixed together within individual depots (Ussar et al., 2014), and a more complete understanding of the cell surface properties and gene expression patterns of those cells is required. In this study, we isolated white and brown adipocytes form inguinal white fat tissue and interscapular brown fat tissue, respectively. In our immunofluorescence staining experiment, Asc1 in the white adipocytes was mainly localized in the nuclei (Figure 2A), and the uniform staining of brown adipocytes was possibly a nonspecific result (Figure 2B). The fluorescence signal of Ucp1 was observed in both the brown and white adipocytes (Figure $2 \mathrm{C}$ and D). Furthermore, as shown Figure 4, a significant difference in the expression levels of both the Asc1 gene and the Ucp1 gene was detected between white adipocytes and brown adipocytes. This result indicates that Asc1 and Ucp1 may serve as useful markers for the characterization of white and brown adipocytes.

Microtubules, which are composed of $\alpha, \beta$ tubulin heterologous dimers, are one of the components of the cytoskeleton (Nogales et al., 1999). Microtubules play a crucial role in maintaining cell shape, intracellular organelle transport (Rodionov et al., 1993), mitosis and chromosome separation (Goshima and Vale, 2003), etc. $\alpha$-tubulin is usually used as an endogenous control (Shen et al., 2010), because its expression level is relatively constant in most tissues (Coker and Davies, 2003). The differentiation of 3T3-F442A preadipocytes is characterized by numerous enzymatic events and by a programmed change in cell morphology from a fibroblastic form to a nearly spherical shape. Accompanying this morphological change are large and specific decreases in biosynthetic rates for $\alpha$ and $\beta$ tubulin (Spiegelman and Farmer, 1982). In this study, we observed 
clear differences in the amount of $\alpha$-tubulin between the white and brown adipocytes, and lipid droplets were confirmed by Oil Red-O staining in both the white and brown adipocytes. Therefore, we speculate that the number of lipid droplets may be related to the differences in $\alpha$-tubulin expression observed in the white and brown adipocytes (Figure 6).

CD44 is a hyaluronate receptor that is crucial in the development of the neo-extracellular matrix, and it plays a role in numerous pathologic and physiologic events (Strem et al., 2005). CD29, a member of the integrin family, plays a crucial role in therapeutic angiogenesis. In this research, white and brown adipocytes stained positively for CD44 and CD29. Moreover, the results were negative for endothelial cell markers such as CD34 and the major histocompatibility complex class II (HLA-DR). These results show that white and brown adipocytes are not derived from circulating stem cells (Peng and Huard, 2004), and prove that those cells are not contaminated with endothelial cells (Yang et al., 2011).

In conclusion, through immunofluorescence staining, quantitative real-time PCR, and western blotting analysis, we have demonstrated that Asc1 and Ucp1 may serve as useful markers for the characterization of white and brown adipocytes, which have different gene expression signatures. In the future, white and brown adipocytes may be useful cell models for researching the mechanisms involved in obesity.

\section{Conflicts of interest}

The authors declare no conflict of interest.

\section{ACKNOWLEDGMENTS}

We are grateful to Dr. XiangWei Kong (University of Inner Mongolia) for technical assistance. Research supported by the National Transgenic Project of China (\#2014ZX08008-00).

\section{REFERENCES}

Atit R, Sgaier SK, Mohamed OA, Taketo MM, et al. (2006). Beta-catenin activation is necessary and sufficient to specify the dorsal dermal fate in the mouse. Dev. Biol. 296: 164-176. http://dx.doi.org/10.1016/j.ydbio.2006.04.449

Attie AD and Scherer PE (2009). Adipocyte metabolism and obesity. J. Lipid Res. 50 (Suppl): S395-S399. http://dx.doi. org/10.1194/jir.R800057-JLR200

Au-Yong IT, Thorn N, Ganatra R, Perkins AC, et al. (2009). Brown adipose tissue and seasonal variation in humans. Diabetes 58: 2583-2587. http://dx.doi.org/10.2337/db09-0833

Caballero B (2007). The global epidemic of obesity: an overview. Epidemiol. Rev. 29: 1-5. http://dx.doi.org/10.1093/epirev/ $\underline{\mathrm{mxm} 012}$

Cinti S (2005). The adipose organ. Prostaglandins Leukot. Essent. Fatty Acids 73: 9-15. http://dx.doi.org/10.1016/j. plefa.2005.04.010

Coker JS and Davies E (2003). Selection of candidate housekeeping controls in tomato plants using EST data. Biotechniques 35: 740-742, 744, 746 passim.

Elabd C, Chiellini C, Carmona M, Galitzky J, et al. (2009). Human multipotent adipose-derived stem cells differentiate into functional brown adipocytes. Stem Cells 27: 2753-2760. http://dx.doi.org/10.1002/stem.200

Faust IM, Johnson PR, Stern JS and Hirsch J (1978). Diet-induced adipocyte number increase in adult rats: a new model of obesity. Am. J. Physiol. 235: E279-E286.

Gesta S, Tseng YH and Kahn CR (2007). Developmental origin of fat: tracking obesity to its source. Cell 131: 242-256. http:/l dx.doi.org/10.1016/j.cell.2007.10.004

Golozoubova V, Hohtola E, Matthias A, Jacobsson A, et al. (2001). Only UCP1 can mediate adaptive nonshivering thermogenesis in the cold. FASEB J. 15: 2048-2050. 
Goshima G and Vale RD (2003). The roles of microtubule-based motor proteins in mitosis: comprehensive RNAi analysis in the Drosophila S2 cell line. J. Cell Biol. 162: 1003-1016. http://dx.doi.org/10.1083/jcb.200303022

Guerra C, Koza RA, Yamashita H, Walsh K, et al. (1998). Emergence of brown adipocytes in white fat in mice is under genetic control. Effects on body weight and adiposity. J. Clin. Invest. 102: 412-420. http://dx.doi.org/10.1172/JCI3155

Haas B, Schlinkert P, Mayer P and Eckstein N (2012). Targeting adipose tissue. Diabetol. Metab. Syndr. 4: 43. http://dx.doi. org/10.1186/1758-5996-4-43

Nie YW, Ding XB, Ge XG, Fan HL, et al. (2013). Enhanced expression of MYF5 and MYOD1 in fibroblast cells via the forced expression of bos taurus MYF5. Cell Biol. Int. 37: 972-976. http://dx.doi.org/10.1002/cbin.10124

Nogales E, Whittaker M, Milligan RA and Downing KH (1999). High-resolution model of the microtubule. Cell 96: 79-88. http:// dx.doi.org/10.1016/S0092-8674(00)80961-7

Peng $\mathrm{H}$ and Huard $\mathrm{J}$ (2004). Muscle-derived stem cells for musculoskeletal tissue regeneration and repair. Transpl. Immunol. 12: 311-319. http://dx.doi.org/10.1016/j.trim.2003.12.009

Richard D and Picard F (2011). Brown fat biology and thermogenesis. Front. Biosci. (Landmark Ed.) 16: 1233-1260. http:// dx.doi.org/10.2741/3786

Rodionov VI, Gyoeva FK, Tanaka E, Bershadsky AD, et al. (1993). Microtubule-dependent control of cell shape and pseudopodial activity is inhibited by the antibody to kinesin motor domain. J. Cell Biol. 123: 1811-1820. http://dx.doi. org/10.1083/jcb.123.6.1811

Rosenwald M, Perdikari A, Rülicke T and Wolfrum C (2013). Bi-directional interconversion of brite and white adipocytes. Nat. Cell Biol. 15: 659-667. http://dx.doi.org/10.1038/ncb2740

Schulz TJ, Huang TL, Tran TT, Zhang H, et al. (2011). Identification of inducible brown adipocyte progenitors residing in skeletal muscle and white fat. Proc. Natl. Acad. Sci. USA 108: 143-148. http://dx.doi.org/10.1073/pnas.1010929108

Seale P, Bjork B, Yang W, Kajimura S, et al. (2008). PRDM16 controls a brown fat/skeletal muscle switch. Nature 454: $961-967$. http://dx.doi.org/10.1038/nature07182

Shan T, Liu W and Kuang S (2013). Fatty acid binding protein 4 expression marks a population of adipocyte progenitors in white and brown adipose tissues. FASEB J. 27: 277-287. http://dx.doi.org/10.1096/fj.12-211516

Shen GM, Jiang HB, Wang XN and Wang JJ (2010). Evaluation of endogenous references for gene expression profiling in different tissues of the oriental fruit fly Bactrocera dorsalis (Diptera: Tephritidae). BMC Mol. Biol. 11: 76. http://dx.doi. org/10.1186/1471-2199-11-76

Spiegelman BM and Farmer SR (1982). Decreases in tubulin and actin gene expression prior to morphological differentiation of 3T3 adipocytes. Cell 29: 53-60. http://dx.doi.org/10.1016/0092-8674(82)90089-7

Strem BM, Hicok KC, Zhu M, Wulur I, et al. (2005). Multipotential differentiation of adipose tissue-derived stem cells. Keio J. Med. 54: 132-141. http://dx.doi.org/10.2302/kjm.54.132

Tang W, Zeve D, Suh JM, Bosnakovski D, et al. (2008). White fat progenitor cells reside in the adipose vasculature. Science 322: 583-586. http://dx.doi.org/10.1126/science.1156232

Ussar S, Lee KY, Dankel SN, Boucher J, et al. (2014). ASC-1, PAT2, and P2RX5 are cell surface markers for white, beige, and brown adipocytes. Sci. Transl. Med. 6: 247ra103. http://dx.doi.org/10.1126/scitranslmed.3008490

Waldén TB, Hansen IR, Timmons JA, Cannon B, et al. (2012). Recruited vs. nonrecruited molecular signatures of brown, "brite," and white adipose tissues. Am. J. Physiol. Endocrinol. Metab. 302: E19-E31. http://dx.doi.org/10.1152/ ajpendo.00249.2011

Wu J, Boström P, Sparks LM, Ye L, et al. (2012). Beige adipocytes are a distinct type of thermogenic fat cell in mouse and human. Cell 150: 366-376. http://dx.doi.org/10.1016/j.cell.2012.05.016

Xue B, Coulter A, Rim JS, Koza RA, et al. (2005). Transcriptional synergy and the regulation of Ucp1 during brown adipocyte induction in white fat depots. Mol. Cell. Biol. 25: 8311-8322. http://dx.doi.org/10.1128/MCB.25.18.8311-8322.2005

Yang XF, He X, He J, Zhang LH, et al. (2011). High efficient isolation and systematic identification of human adipose-derived mesenchymal stem cells. J. Biomed. Sci. 18: 59. http://dx.doi.org/10.1186/1423-0127-18-59 